\title{
Surface Modification of Nano-Hydroxyapatite by Coating Stearic Acid
}

\author{
M. Yousefi ${ }^{1 *}$, N. Modghan², M.H. Ebrahimzadeh² \\ ${ }^{1}$ Department of Orthopaedic Surgery, Mashhad University of Medical Sciences, Mashhad, Iran \\ ${ }^{2}$ Department of Materials Science and Engineering, Faculty of Engineering, Ferdowsi University of Mashhad, Mashhad, Iran
}

Received: 06/01/2020

Accepted: 13/03/2020

Published: 20/03/2020

\begin{abstract}
Todays, researchers are challenging with manufacturing polymeric nanocomposites reinforced with ceramic particles due to two inherent properties of ceramic reinforcement particles, particle agglomeration and incompatibility between hydrophilic ceramic particles and hydrophobic polymeric matrix. So in this study, we used nano-Hydroxyapatite (n-HA) as ceramic material and Stearic acid as amphiphilic material for coating n-HA, hydroxysteric acid (SA) surfactant was used for surface coating particles between the hydrophilic HA powders and the hydrophobic polymers. The surface modification and effect of this method were evaluated by by Fourier transformation infrared (FTIR), x-ray diffractometer (XRD), thermal gravimetric analysis (TGA) and Scanning electron microscopy (SEM). The result of FTIR showed that n-HA surfaces were modified successfully and the modification method had the proper grafting amount according to TGA due to this method of modification will be proper for coating reinforcement particles in polymeric matrix.
\end{abstract}

Keywords: Hydroxyapatite, Stearic acid, Hydrophilic ceramic, Amphiphilic, Stearic acid

\section{Introduction}

Aliphatic polyesters, such as poly(lactic acid) (PLA), poly(glycolic acid) (PGA) and their copolymers (PLGA), are biodegradable and essentially non-toxic one of the main polymer groups, such as bone screws, bone plates and pins made of PLA or PDLLA have been widely used in bone fracture fixation [1-3]. However, PLLA and PDLLA have still their weaknesses, for example for PLLA, although it can be completely degraded in one or two years [4], Moreover, for clinical research, and so far it has been one of the most commonly used in biomedical fields such as bone screws, due to the combination of its bioabsorbabtily, biodegradable, biocompatible .[5]. However, for PLLA, there are still some critical subjects to be solved so as to be used as bone screws in body, for example, its mechanical properties are too low to be sufficient for more demanding load application due to its non-crystallinity, and the poor cell attachment ability [6,7]. To overcome these inherent disadvantages, the prevalent method is to introduce the inorganic fillers into PLLA to fabricate filler/polymer composites, such as hydroxyapatite, _-tricalcium phosphate, bioglass, titanium dioxide, and so on [8-11]. Among the inorganic filler/PLLA composites, nano-hydroxyapatite (n-HA) is a major inorganic component of natural bone, so it was thought to have good bioactivity and osteoconductivity properties due to their chemical and structural similarity to the mineral phase of native bone. Moreover, n-HA is a weak alkali inorganic filler, which can buffer acidic in body[12-14]. Therefore, to improve the shortcomings of PLLA, the n-HA/PLGA composite have been

Corresponding author: M. Yousefi, Department of Orthopaedic Surgery, Mashhad University of Medical Sciences, Mashhad, Iran.

E-mail: yousefi_shiraz@yahoo.com extensively investigated, which are expected to reinforce mechanical properties, improve cell adhesion and endow it with bioactivity as well as adjust the degradation rate by inducing $\mathrm{n}$ HA nanoparticles [15-17]. However, there are two most problematic issues in manufacturing n-HA/PLLA composite, the one is the agglomeration of the HA nanoparticles in the PLLA matrix, and another is a weak adhesion between the hydrophilic $\mathrm{n}$-HA and hydrophobic polymer, which will result in early failure at the interface and thus deteriorate the mechanical properties and limit its load-bearing applications. To solve these problems, it is necessary to hunt for an appropriate modification method for n-HA to improve the dispersion and the compatibility between the filler and the polymer, and it has been becoming the key of research work. Accordingly, many methods have already been applied [18-23], including a diverse class of coupling agents, zirconyl salt, poly acids, dodecyl alcohol, polyethylene glycol and isocyanate, and so on. However, among these techniques, the modification effects were all not very ideal, most of these methods are complex, while the surface of nanoparticles is not well covered, Based on this aim of oure work is to develop a modified coating to potentially enhance the application of nanohydroxyapatite for biomaterials. Therfore n-HA was coated with stearic acid by means of solution mixing, this method is simple and low cost

\section{Materials and Methods \\ 2.1 Materials}

n-HA was prepared on our previous report[24], Briefly, separate solutions of calcium nitrate tetra hydrate $(\mathrm{Ca}$ $\left(\mathrm{NO}_{3}\right)_{2} \cdot 4 \mathrm{H}_{2} \mathrm{O}$; Merck) in water and phosphoric acid $\left(\mathrm{H}_{3} \mathrm{PO}_{4}\right.$; Merck) in ethanol/water (1/4 by mole) were prepared by stirring each for $3 \mathrm{~h}$ and were then mixed together at a stoichiometry of $[\mathrm{Ca}] /[\mathrm{P}] 1 / 41.67$, followed by stirring for $6 \mathrm{~h}$, and aging for 7 days at room temperature, The product was white precipitated 
that were dried at $80 \mathrm{C}^{\circ}$ for $24 \mathrm{~h}$ in oven then were calcined at $600 \mathrm{C}^{\circ}$ for $2 \mathrm{~h}$ using an electrical furnace with heating rate of 10 $\mathrm{c} / \mathrm{min}$ to prepare nano HA powder.

\subsection{The modification of $\mathrm{n}-\mathrm{HA}$}

Firstly, an amphiphilic surfactant SA (C18H36O3; Aldrich) was dissolved in aceton at $50 \mathrm{C}^{\circ}$. (Solution 1). The HA powder was dispersed at $5 \% \mathrm{w} / \mathrm{v}$ in the aceton (solution 2). Then, two solution mixed up together and stirred 4 hours at $55 \mathrm{C}^{\circ}$, in period of stirring volume of aceton should be constant, then solution was washed whit chloroform and cyclohexane, respectively.

In order to study the phase evolution and formation of crystalline HA, the produced powders were analyzed by using IR spectroscopy (Buck 500, KBr) in the range of 500-4000 $\mathrm{cm}^{-1}$. Phase identification of the calcined gels was performed using the X-ray diffractometer (XRD, Philips, X'pert Pro, CuK_) at a scanning speed of $1 \circ 2 \theta \mathrm{min}-1$ from $10^{\circ}$ to $60^{\circ}$. electron microscopy (SEM S 360, Oxford-England) was used for morphology analysis of products.

\section{Results and Discussion \\ 3.1 XRD analyse}

The XRD pattern Hydroxyapatite was shown in Figure 1. The pattern indicate the presence of pure hydroxyapatite in obtained powder.

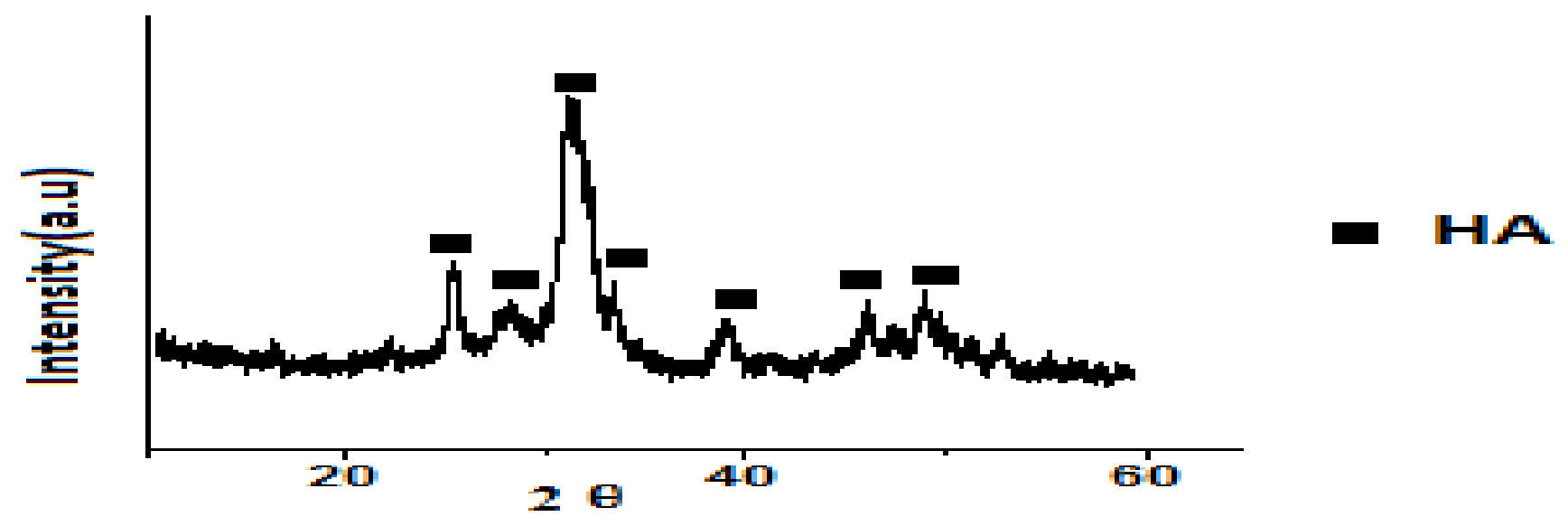

Figure 1. XRD patterns of HA powder

\subsection{Morphology and particle size}

For proper amount of nanoparticle coating, it is necessary to measure the particle size of the particles to assess appropriate amount of SA, otherwise the surfactant amount will be less and coating will be incomplete. In The Fig. 2 was shown morphology of n-HA that had spherical shape, and mean size nanoparticles measured 30 nanometres.

\subsection{IR analyse}

The IR spectra of n-HA and g-n-HA are shown in Fig 3. For n-HA (shown in Fig. 3(a)), the spectroscopic band are observed around the $3568 \mathrm{~cm}^{-1}$ and $632 \mathrm{~cm}^{-1}$, which are described to the stretching vibration of the hydroxyl group $(\mathrm{OH})$ of n-HA, and the peak at $3421 \mathrm{~cm}^{-1}$ and $1637 \mathrm{~cm}^{-1}$ are both attributed to adsorbed water. The peak at $875 \mathrm{~cm}^{-1}$ for $\mathrm{HPO}_{4}{ }^{2-}, 1094 \mathrm{~cm}^{-1}$, $1032 \mathrm{~cm}^{-1}, 604 \mathrm{~cm}^{-1}$ and $564 \mathrm{~cm}^{-1}$ are all attributed to $\mathrm{PO}_{4}{ }^{3-}$ peak. In addition, $1452 \mathrm{~cm}-1$ and $1413 \mathrm{~cm}-1$ double split peaks belong to $\mathrm{CO}_{3}$ asymmetric stretch peak, which indicated $\mathrm{CO}_{3}{ }^{2-}$ entered HA lattice. These results are in accordance with that of nHA in literature. After surface modification, the above characteristic peaks of n- HA are all observed in the spectra of $\mathrm{g}$ n-HA, which suggested n-HA had not been changed. Compared with the spectra of g-n-HA, for the g1-n-HA (shown in the Fig. $3(\mathrm{~b})$ ), a new absorptions emerges at $1558 \mathrm{~cm}^{-1}$, implying the formation of calcium carboxylate on the surface of n-HA.

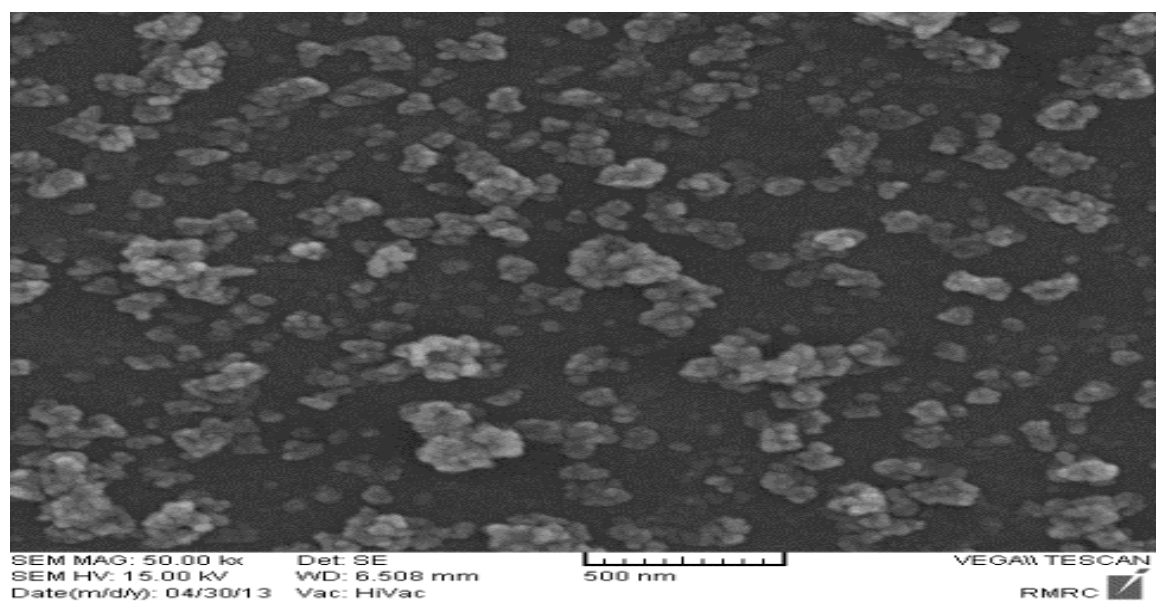

Figure 2. SEM image of calcined HA powders 


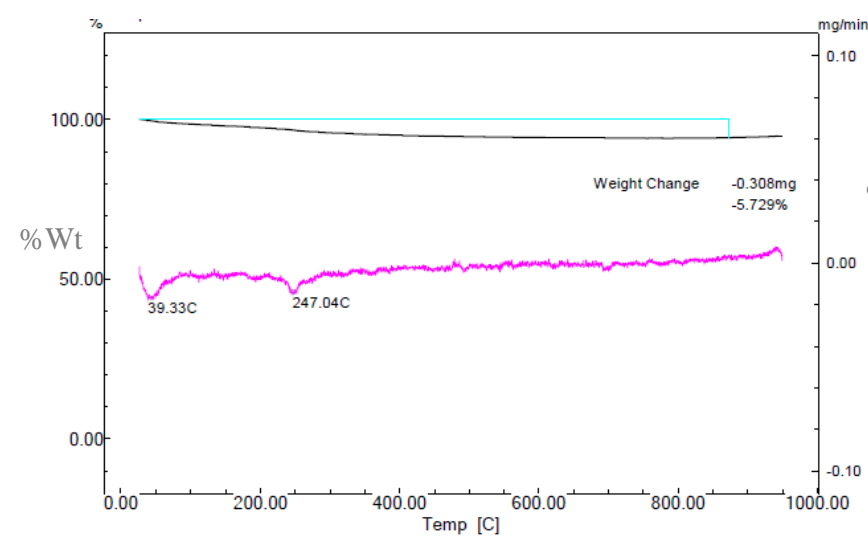

(a)

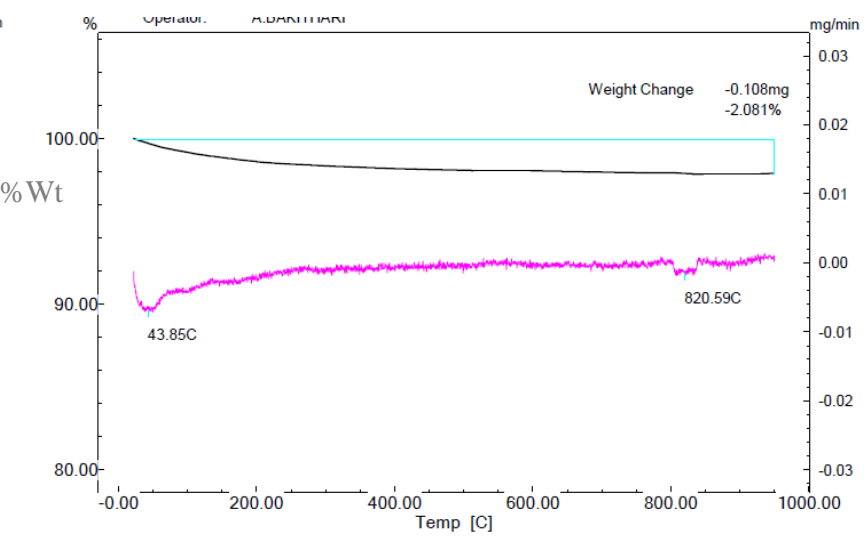

(b)

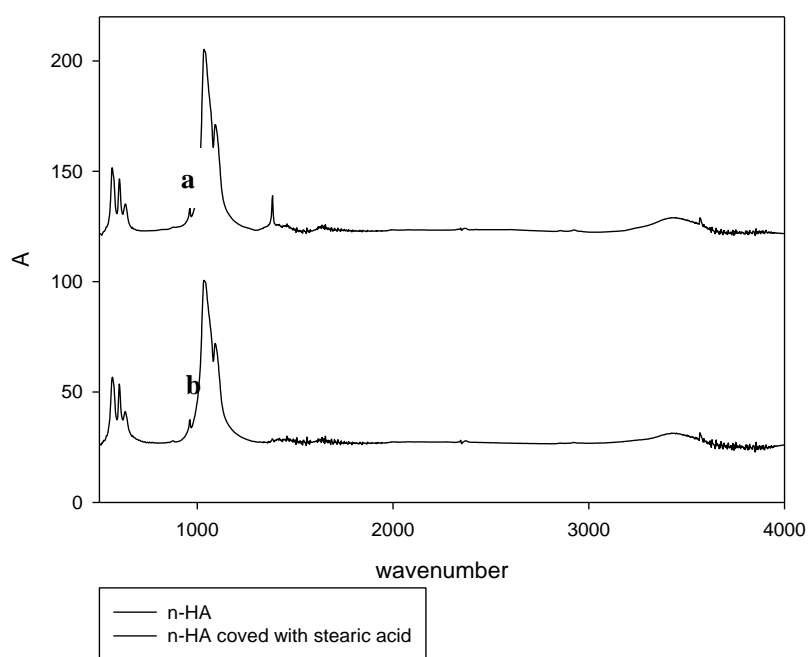

(c)

Figure 3. The IR spectra of (a) g-n-HA, (b) n-HA and (c) FTIR curves of (a) unmodified n-HA, (b) n-HA modified with stearic acid

\subsection{TGA}

The amounts of grafted HSA were measured by TGA, as shown in Fig. 4. According to the TGA curve, the weight loss of n-HA is $2.08 \%$, and the g-n-HA, $5.729 \%$, Thus, the surfacegrafted amounts of g-n-HA is calculated as follows: The grafting amounts = weight loss\% (gn-HA)-Weight loss \% (n-HA), which is 3.649. Obviously, it is further proved that n-HA surface was successful grafted in quantitatively.

\section{Conclusions}

Nanoparticles of hydroxyapatite were coated with a simple and efficient method which result of TGA and FTIR confirmed appropriate coating.

\section{Ethical issue}

Authors are aware of, and comply with, best practice in publication ethics specifically with regard to authorship (avoidance of guest authorship), dual submission, manipulation of figures, competing interests and compliance with policies on research ethics. Authors adhere to publication requirements that submitted work is original and has not been published elsewhere in any language.

\section{Competing interests}

The authors declare that there is no conflict of interest that would prejudice the impartiality of this scientific work.

\section{Authors' contribution}

All authors of this study have a complete contribution for data collection, data analyses and manuscript writing.

\section{References}

[1] Fan Y, Xiu K, Duan H, Zhang M. Biomechanical and histological evaluation of the application of biodegradable poly-L-lactic cushion to the plate internal fixation for bone fracture healing. Clinical Biomechanics. 2008 Jan 1;23:S7-16.

[2] Handolin L, Pohjonen T, Partio EK, Arnala I, Törmälä P, Rokkanen P. The effects of low-intensity pulsed ultrasound on bioabsorbable self-reinforced poly l-lactide screws. Biomaterials. 2002 Jul 1;23(13):2733-6.

[3] Rasse M, Moser D, Zahl C, Gerlach KL, Eckelt U, Loukota R. Resorbable poly (D, L) lactide plates and screws for osteosynthesis of condylar neck fractures in sheep. British Journal of Oral and Maxillofacial Surgery. 2007 Jan 1;45(1):35-40.

[4] Maurus, Peter B., and Christopher C. Kaeding. "Bioabsorbable implant material review." Operative Techniques in Sports Medicine 12, no. 3 (2004): 158-160.

[6] Jeong SI, Kim SY, Cho SK, Chong MS, Kim KS, Kim H, Lee SB, Lee YM. Tissue-engineered vascular grafts composed of marine collagen and PLGA fibers using pulsatile perfusion bioreactors. Biomaterials. 2007 Feb 1;28(6):1115-22.

[7] Wan Y, Qu X, Lu J, Zhu C, Wan L, Yang J, Bei J, Wang S Characterization of surface property of poly (lactide-co-glycolide) after oxygen plasma treatment. Biomaterials. 2004 Aug $1 ; 25(19): 4777-83$ 
[8] Petricca SE, Marra KG, Kumta PN. Chemical synthesis of poly (lactic-co-glycolic acid)/hydroxyapatite composites for orthopaedic applications. Acta Biomaterialia. 2006 May 1;2(3):277-86.

[9] Pang L, Hu Y, Yan Y, Liu L, Xiong Z, Wei Y, Bai J. Surface modification of PLGA/ $\beta$-TCP scaffold for bone tissue engineering: hybridization with collagen and apatite. Surface and Coatings Technology. 2007 Oct 15;201(24):9549-57.

[10] Boccaccini AR, Blaker JJ, Maquet V, Day RM, Jérôme R. Preparation and characterisation of poly (lactide-coglycolide)(PLGA) and PLGA/Bioglass® composite tubular foam scaffolds for tissue engineering applications. Materials Science and Engineering: C. 2005 Jan 1;25(1):23-31.

[11] Torres FG, Nazhat SN, Fadzullah SS, Maquet V, Boccaccini AR. Mechanical properties and bioactivity of porous PLGA/TiO2 nanoparticle-filled composites for tissue engineering scaffolds. Composites science and technology. 2007 May 1;67(6):1139-47.

[12] Huang J, Best SM, Bonfield W, Brooks RA, Rushton N, Jayasinghe $\mathrm{SN}$, Edirisinghe MJ. In vitro assessment of the biological response to nano-sized hydroxyapatite. Journal of Materials Science: Materials in Medicine. 2004 Apr 1;15(4):441-5.

[13] Orr TE, Villars PA, Mitchell SL, Hsu HP, Spector M. Compressive properties of cancellous bone defects in a rabbit model treated with particles of natural bone mineral and synthetic hydroxyapatite. Biomaterials. 2001 Jan 1;22(14):1953-9.

[14] Palmer LC, Newcomb CJ, Kaltz SR, Spoerke ED, Stupp SI. Biomimetic systems for hydroxyapatite mineralization inspired by bone and enamel. Chemical reviews. 2008 Nov 12;108(11):4754-83.

[15] Hong Z, Zhang P, Liu A, Chen L, Chen X, Jing X. Composites of poly (lactide-co-glycolide) and the surface modified carbonated hydroxyapatite nanoparticles. Journal of Biomedical Materials Research Part A. 2007 Jun 1;81(3):515-22.

[16] Zhang P, Hong Z, Yu T, Chen X, Jing X. In vivo mineralization and osteogenesis of nanocomposite scaffold of poly (lactide-coglycolide) and hydroxyapatite surface-grafted with poly (L-lactide). Biomaterials. 2009 Jan 1;30(1):58-70.

[17] Cui Y, Liu Y, Cui Y, Jing X, Zhang P, Chen X. The nanocomposite scaffold of poly (lactide-co-glycolide) and hydroxyapatite surfacegrafted with L-lactic acid oligomer for bone repair. Acta biomaterialia. 2009 Sep 1;5(7):2680-92.

[18] Borum L, Wilson Jr OC. Surface modification of hydroxyapatite Part II. Silica. Biomaterials. 2003 Sep 1;24(21):3681-8.

[19] Misra DN. Adsorption of zirconyl salts and their acids on hydroxyapatite: use of the salts as coupling agents to dental polymer composites. Journal of dental research. 1985 Dec;64(12):1405-8.

[20] Liu Q, Bakker D, Van Toledo M, van BLITTERSWIJK CA Polyacids as bonding agents in hydroxyapatite polyester-ether (PolyactiveTM 30/70) composites. Journal of materials science: materials in medicine. 1998 Jan 1:9(1):23-30.

[21] Borum-Nicholas L, Wilson Jr OC. Surface modification of hydroxyapatite. Part I. Dodecyl alcohol. Biomaterials. 2003 Sep 1;24(21):3671-9.

[22] Wang X, Li Y, Wei J, De Groot K. Development of biomimetic nano-hydroxyapatite/poly (hexamethylene adipamide) composites. Biomaterials. 2002 Dec 1;23(24):4787-91.

[23] Dong GC, Sun JS, Yao CH, Jiang GJ, Huang CW, Lin FH. A study on grafting and characterization of HMDI-modified calcium hydrogenphosphate. Biomaterials. 2001 Dec 1;22(23):3179-89.

[24] Yousefi K, Zebarjad SM, Vahdati Khaki J. Effect of polyethylene glycol and acetic acid on morphology of nanoparticle Hydroxyapatite synthesized by sol-gel. In4th International Conference on Nanostructures (ICNS4 2012 Mar 12. 